\title{
Effect of filler addition on the compressive and impact properties of glass fibre reinforced epoxy
}

\author{
NIKHIL GUPTA*, BALRAJ SINGH BRAR ${ }^{\dagger}$ and EYASSU WOLDESENBET \\ Department of Mechanical Engineering, Louisiana State University, Baton Rouge, LA 70803, USA \\ ${ }^{\dagger}$ Baba Banda Singh Engineering College, Fateh Garh Saheb, Punjab 140 407, India
}

MS received 6 June 2000; revised 31 January 2001

\begin{abstract}
Flyash is incorporated in glass fibre reinforced epoxies to study their response to the filler addition. Low cost of flyash can reduce the overall cost of the component. Only very low volume fractions of filler are investigated in the present study. To obtain further clarification of the observed phenomenon, another abundantly available low cost material, calcium carbonate is incorporated in one set of the specimens. Compressive strength of the material is found to decrease, whereas steep increase in impact strength is observed by introduction of very small quantity of fillers. Specimens containing calcium carbonate are tested for impact properties only. Effect of specimen aspect ratio on the compressive strength values is also studied by testing specimens of three different aspect ratios. Scanning electron microscopic observations are taken to develop a better understanding of the phenomena taking place in the material system at microscopic level.
\end{abstract}

Keywords. Fillers; flyash; compression test; impact test; fibre reinforced epoxies.

\section{Introduction}

Polymers found their way in a large number of applications by virtue of their lower density. Their lightweight makes them suitable for weight sensitive structural applications. High cost of polymers is sometimes a limiting factor in their use for commercial applications. Use of low cost easily available fillers may be useful to bring the cost of component down. Study of effect of such filler addition is necessary to ensure that the mechanical properties are not affected adversely by such an addition. Available references suggest investigations on a large number of materials to be used as fillers in polymers (Katz and Milewski 1987) but only a few of them deal with the material systems containing fibres and fillers simultaneously (Gupta et al 1999). The purpose of use of fillers can be divided into two basic categories, first, to improve the properties of the material and second, to reduce the cost of component.

In the present investigation, flyash and calcium carbonate are selected as the filler materials. Both these materials are abundantly available and have very low cost. In all the cases discontinuous glass fibres are also incorporated in the material system. Flyash is generated in large quantities in the thermal power plants and has found applications mainly in construction sector only. Some available references deal with the experimental aspects of the flyash filled materials (Srivastava et al 1988; Srivastava 1992) or modelling of particulate composites (Monette and

\footnotetext{
*Author for correspondence
}

Anderson 1993; Vrastsanos and Farris 1993; Wong and Truss 1994), but no attempt in the literature is found for critically analysing the fracture behaviour and fracture characteristics of such materials.

In an attempt to have a better understanding of behaviour of the composites having flyash or calcium carbonate as filler, material was tested under both static and dynamic loading conditions. Scanning electron microscopy gives a better view of the phenomena taking place in the materials during loading. Specimens were thoroughly investigated under scanning electron microscope after performing the mechanical tests.

\section{Materials}

\subsection{Epoxy resin}

The matrix material used for the fabrication of composite slabs consisted of low temperature curing epoxy resin (Araldite LY552) and corresponding hardener (HY951) supplied by Hindustan Ciba-Geigy. Resin and hardener were mixed in a ratio of $100: 10$ by weight as recommended by the supplier. Density of the resin system was $1 \cdot 1 \mathrm{~g} / \mathrm{cc}$.

\subsection{Glass fibres}

$E$-glass fibres having epoxy compatible coating were taken for incorporation as reinforcement in the material system. The fibres having diameter of about $10 \mu \mathrm{m}$ were cut into $2.54 \mathrm{~cm}$ size. Density of glass fibres was $2.54 \mathrm{~g} / \mathrm{cc}$. 


\subsection{Flyash}

Flyash was obtained from thermal power plant at Punjab (India). Measured density of flyash particles was $2 \cdot 0 \mathrm{~g} / \mathrm{cc}$. The chemical composition of the flyash supplied by the power plant is given in table 1. According to the composition this flyash can be classified in class-F category (ASTM C618), as the total content of silica and alumina together is more than $70 \%$.

\subsection{Equipment}

Two moulds of size $154 \times 78 \times 12 \mathrm{~mm}$ were prepared for casting the composite slabs. All the inner surfaces of the mould were covered with cello tape to avoid any possible contact between resin and mould. Silicone grease was applied as release agent.

\section{Processing}

Resin and hardener were mixed in appropriate proportions. After very slow mixing of resin and hardener to avoid formation of bubbles in the resin system, first fibres were added in small quantities. If fillers are mixed in the resin first and then fibres are added, in that case wetting of fibres may be a problem. For this reason complete amount of fibres was added and mixed thoroughly and then only fillers were added in the system. Small size and spherical shape of the flyash particles facilitate their good mixing and wetting. Mixture was stirred for prolonged time at slow speed to ensure good mixing and wetting of all components by resin and get uniform quality dough. The dough was then transferred to the moulds and was allowed to cure at room temperature for $24 \mathrm{~h}$.

First slab was cast with glass fibres only to get data for the purpose of comparison with the property data of the composite slabs having flyash also. Two different concentrations of flyash were selected for the work, 2.5 and 5 vol.\%. Resin and fibre proportions were kept same in all the cases.

\section{Experimental}

In the present study compression and impact tests were carried out to study the mechanical behaviour of the material. For the compression test, square cross-section specimens having length and width of $10 \mathrm{~mm}$ each were prepared. To study the effect of specimen aspect (height/ width) ratio of the compressive strength values, three different specimen heights, 15, 20 and $25 \mathrm{~mm}$ were taken, giving aspect ratios of $1.5,2.0$ and 2.5 respectively. A 100 ton capacity servo-hydraulic Universal Testing Machine was used to perform the testing. Constant crosshead speed of $1 \mathrm{~mm} / \mathrm{min}$ was maintained during the testing in agreement with the ASTM standard. Six specimens of each type were tested.

For the impact testing, Izod test was performed on the unnotched specimens as recommended by ASTM standard for the rigid plastics. Specimen for this test had dimensions of $10 \times 10 \times 75 \mathrm{~mm}^{3}$. Six specimens of each type were tested in accordance with the same standard.

\section{Results}

Majority of flyash particles have a cavity at the centre of the particle, which leads to a reduction in density of the material. Also, the particles have a very small particle size. The material used in the investigation had majority of particles in the size range $1-20 \mu \mathrm{m}$. It is found that the flyash particles can have three different types of structures as shown in figure 1. Particles of first type are solid

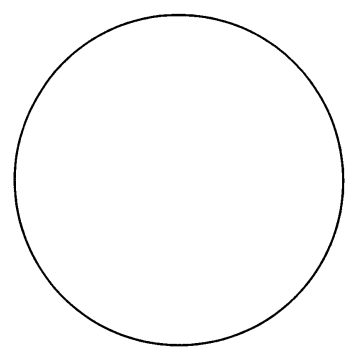

(a)

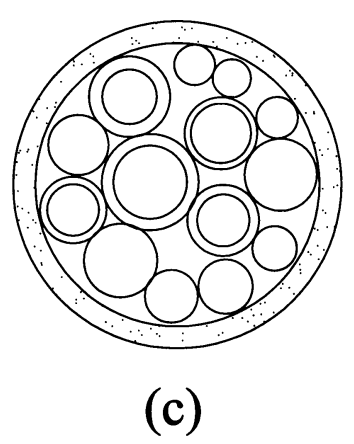

(c)

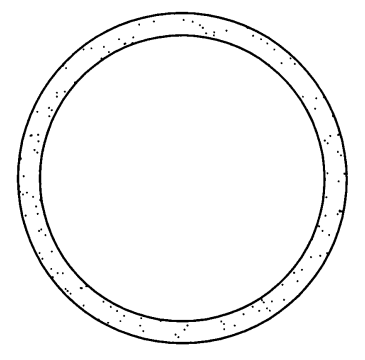

(b)
Table 1. Composition of flyash.

\begin{tabular}{lc}
\hline Compound & Weight $\%$ \\
\hline Silica & $59 \cdot 50$ \\
$\mathrm{Alumina}_{\mathrm{Fe}_{2} \mathrm{O}_{3}}$ & $20 \cdot 30$ \\
$\mathrm{Titanium}_{\mathrm{CaO}}$ & $6 \cdot 50$ \\
Potassium oxide & $1 \cdot 28$ \\
$\mathrm{Mg}$ and $\mathrm{MgO}$ & $0 \cdot 12$ \\
$\mathrm{Na} 2$ & $0 \cdot 50$ \\
Sulfates & $0 \cdot 29$ \\
Phosphates & $0 \cdot 34$ \\
Unburnt coal & $0 \cdot 05$ \\
\hline
\end{tabular}

Figure 1. Structure of flyash particles (a) solid, (b) cenosphere (hollow) and (c) plerosphere. 
(figure 1a), but fraction of solid particles is very less compared to the other two structures. Second type of structure is hollow and is called cenosphere (figure 1b). Third type of structure called plerosphere is also hollow but the cavity in the centre of the particle is filled with smaller diameter particles, which may be solid or hollow (figure 1c). Helmuth (1987) has described these structures in detail.

\subsection{Compression test}

Results of compression test are shown in table 2 . Compression tests were carried out for three different specimen aspect ratios. Remarkable differences can be seen in the values of compressive strength with different flyash contents and also with different aspect ratios. The data presents an interesting trend. It can be noticed that for the specimens containing glass fibres only, the compressive strength values are nearly same for aspect ratios of 2.0 and $2 \cdot 5$. For lower aspect ratio, i.e. $1 \cdot 5$, compressive strength is considerably low. With the addition of flyash in small volume fraction again it is seen that the compressive strength values remained minimum for aspect ratio value of $1 \cdot 5$. A maximum is seen at the aspect ratio of 2 . For aspect ratio of $2 \cdot 5$, the compressive strength values are found to be intermediate to that at 1.5 and 2 values. In case of discontinuous fibre composites, length of fibres is closely related to the length of test specimens. If specimens are too small, considerable shortening of fibres can take place near the faces of the specimen giving unreliable values for compressive strength. If the aspect ratio is very high, probability of buckling effects of the specimen during test will be considerable. For this reason pronounced effect of aspect ratio of the specimen on the compressive strength can be seen. It also indicates that not only aspect ratio, but the dimensions of the specimens are also important in case of discontinuous fibre composites.

Table 2. Compressive strength of the fibre reinforced epoxy with and without flyash at different specimen aspect ratios.

\begin{tabular}{|c|c|c|c|c|c|}
\hline $\begin{array}{l}\text { Slab } \\
\text { no. }\end{array}$ & $\begin{array}{l}\text { Filler } \\
\text { type }\end{array}$ & $\begin{array}{l}\text { Filler vol. } \\
\text { fraction }\end{array}$ & $\begin{array}{l}\text { Fibre vol. } \\
\text { fraction }\end{array}$ & $\begin{array}{l}\text { Specimen } \\
h / b \text { ratio }\end{array}$ & $\begin{array}{c}\text { Compressive } \\
\text { strength } \\
(\mathrm{MPa})\end{array}$ \\
\hline 1 & None & 0 & $4 \cdot 2$ & $\begin{array}{l}1 \cdot 5 \\
2 \cdot 0 \\
2 \cdot 5\end{array}$ & $\begin{array}{r}75 \cdot 58 \\
105 \cdot 90 \\
105 \cdot 26\end{array}$ \\
\hline 2 & Flyash & $2 \cdot 6$ & $4 \cdot 1$ & $\begin{array}{l}1 \cdot 5 \\
2 \cdot 0 \\
2 \cdot 5\end{array}$ & $\begin{array}{l}83 \cdot 49 \\
98 \cdot 88 \\
94 \cdot 12\end{array}$ \\
\hline 3 & Flyash & $5 \cdot 1$ & $3 \cdot 98$ & $\begin{array}{l}1 \cdot 5 \\
2 \cdot 0 \\
2 \cdot 5\end{array}$ & $\begin{array}{l}47 \cdot 02 \\
76 \cdot 77 \\
66.96\end{array}$ \\
\hline
\end{tabular}

It can also be concluded that the compressive strength has reduced considerably with the increase in the flyash content of the material. This difference is small at flyash content of $2.6 \%$ volume fraction, but at $5.1 \%$ volume fraction it becomes very large and values of compressive strength decrease by about $35 \%$ compared to that of unfilled specimens. These observations match with the simulation results obtained by Monette and Anderson (1993). Result of their simulation showed that the decrease in the strength of the material is very sharp when filler volume fraction is low. With increase in filler volume fraction, it becomes nearly constant after initial steep decrease.

Rigidity and crushing strength of flyash particles are much higher compared to that of epoxy materials. In general, increase in the compressive strength of the epoxy can be expected by the addition of flyash particles in it. Reverse trend of experimental data should not confuse us here. The difference is primarily due to the small volume fraction of the flyash in the material system where fibres are also present. Fibres remain the major load carrier in the structure even after filler addition. At such a small volume fraction of flyash, when the size of the particle is considerably small, it does not offer any substantial barrier to the deforming epoxy during compressive loading of the specimen. At the fracture point, fibre failure remains prominent (figure 2). Evidence of plastic deformation of epoxy resin can be seen very clearly by the river pattern formation in the matrix (figure 3 ). For load bearing purpose, at the small volume fractions flyash particles seem to be ineffective. Dispersion of these particles is good in the structure. Substantial elastic and then plastic deformation has taken place in the matrix materials and small particles in such a low proportion are not able to resist them. On the contrary, due to their regular spherical shape, they may be able to move around easily with the matrix. On the entire fractured surface, broken fibre pieces can be seen abundantly.

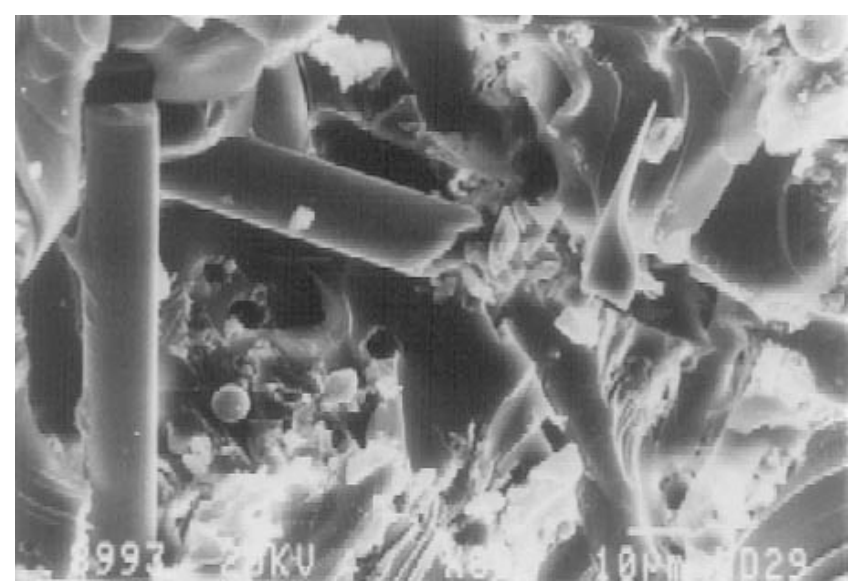

Figure 2. Scanning electron micrograph showing compressive failure features. Pieces of broken fibres and some flyash particles can be seen. 


\subsection{Impact test}

Results of the impact test of these materials is given in table 3. Remarkable difference in the impact strength of the material can be seen with the addition of small quantity of flyash. The value of impact strength has increased by more than $300 \%$. Polymer based composite materials when subjected to impact type of loading conditions, energy is absorbed in the process of plastic deformation of matrix material, debonding at matrix/reinforcement interface and in the fracture of reinforcing material. The phenomenon that absorbs least amount of energy for its occurrence becomes prominent and leads to fracture. In case when small particles are incorporated in the matrix, crack length increases considerably during the process of fracture. For the same volume fraction of the filler material, the smaller the size of filler particles, the larger will be their surface area, hence higher will be the increase in crack length leading to increase in energy absorption before fracture. If the compatibility of the filler particles with the matrix material is not good, the crack blunting at the filler particle location will play an important role and again leads to the same conclusion. In case of flyash particles, compatibility with the matrix resin seems to be good through scanning electron microscopic observation (figure 4 ). In the micrographs taken on the surface of the impact-tested specimens long protru-

Table 3. Impact strength of the fibre reinforced epoxy with and without fillers.

\begin{tabular}{lcccc}
\hline $\begin{array}{l}\text { Slab } \\
\text { no. }\end{array}$ & $\begin{array}{c}\text { Filler } \\
\text { type }\end{array}$ & $\begin{array}{c}\text { Filler vol. } \\
\text { fraction }\end{array}$ & $\begin{array}{c}\text { Fibre vol. } \\
\text { fraction }\end{array}$ & $\begin{array}{c}\text { Impact strength } \\
\left(\mathrm{J} / \mathrm{mm}^{2}\right)\end{array}$ \\
\hline 1 & None & 0 & $4 \cdot 20$ & $5 \times 10^{-3}$ \\
2 & Flyash & $2 \cdot 6$ & $4 \cdot 10$ & $15 \cdot 2 \times 10^{-3}$ \\
3 & Flyash & $5 \cdot 1$ & 3.98 & $17 \cdot 6 \times 10^{-3}$ \\
4 & $\mathrm{CaCO}_{3}$ & $9 \cdot 1$ & $3 \cdot 80$ & $12 \times 10^{-3}$ \\
\hline
\end{tabular}

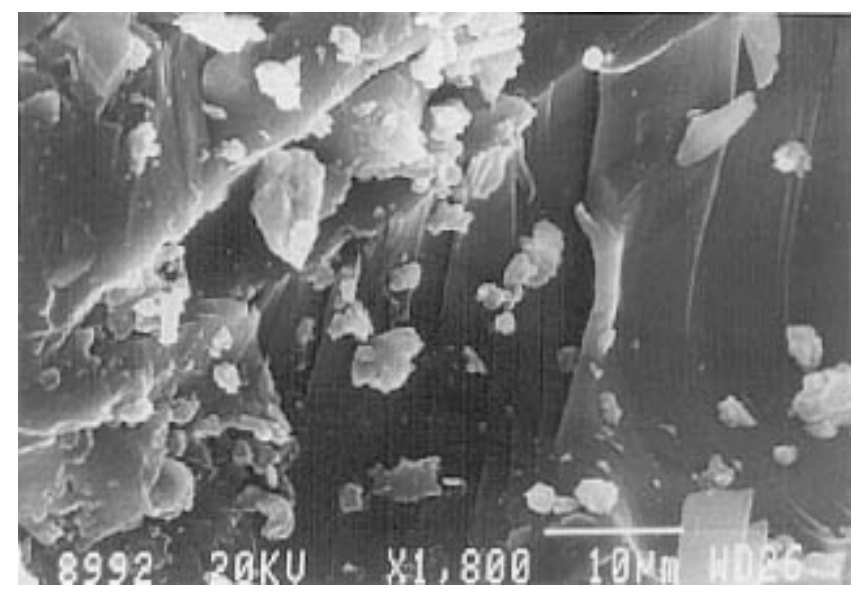

Figure 3. Scanning electron micrograph showing plastic deformation in matrix epoxy resin. ding fibres and holes in the matrix resin give evidence of fibre pull out during the test (figure 5). Despite good dispersion, large number of exposed flyash particles on the fractured surface (figure 6) can also be seen. This validates the argument that growing crack front, during the process of fracture, had to change its path numerous times after interaction with flyash particles, leading to increase in effective crack length and hence, higher absorption of energy in the process of fracture. Flyash particles are rigid and have much higher fracture strength compared to the epoxy resin so they did not fracture by the growing crack. If the fracture strength of filler particle is less than that of the epoxy resin, particles will tend to fracture, again consuming energy. Increase in impact strength of specimen will depend on the fracture strength of the filler material.

To further investigate this argument, calcium carbonate particles were incorporated in similar material system. Calcium carbonate particles have particles size more than that of flyash particles and have a plate like structure. In

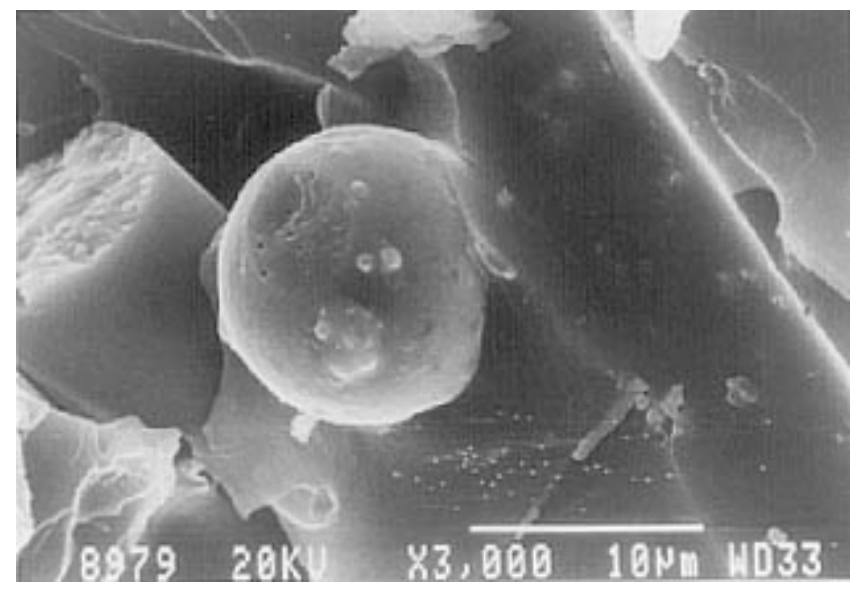

Figure 4. Micrograph showing that flyash-matrix compatibility is better than fibre-matrix.

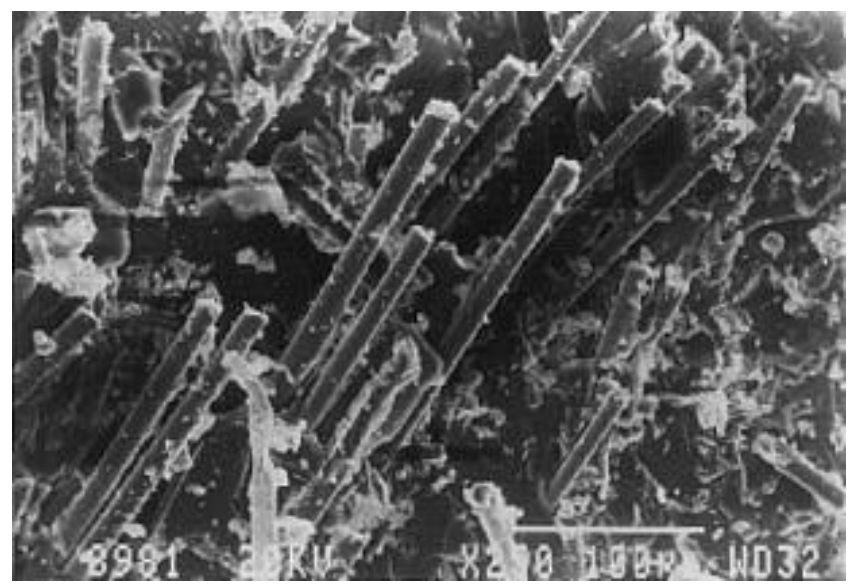

Figure 5. Fibre pull-out on the surface of impact tested specimens. 


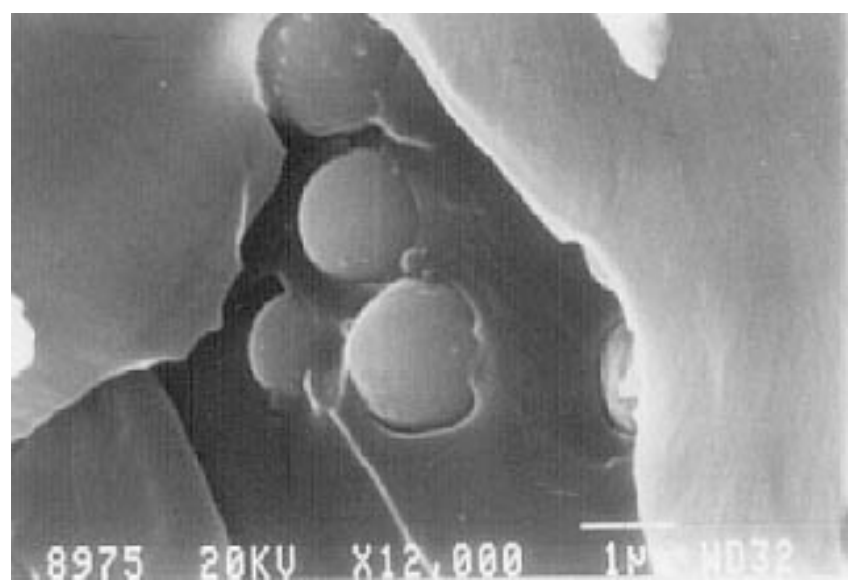

Figure 6. Presence of flyash particles on the fracture surface of impact tested specimen.

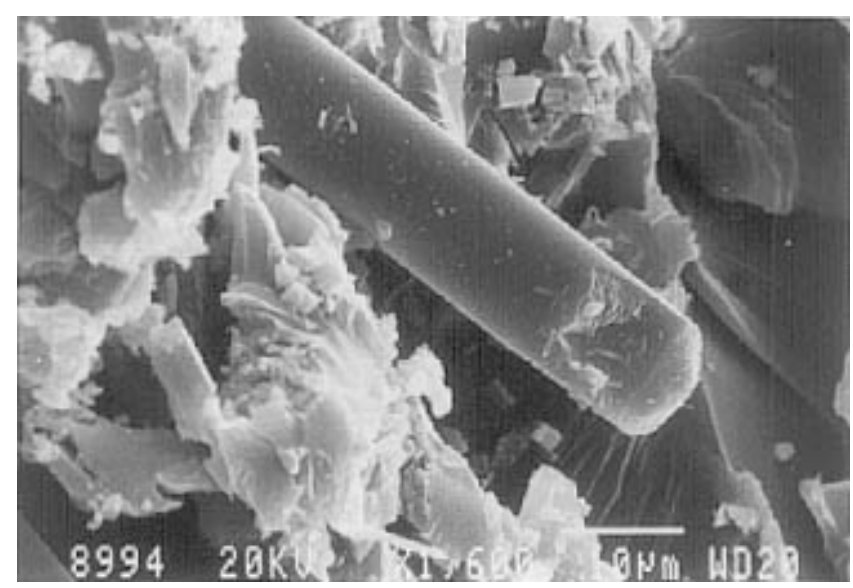

Figure 7. Calcium carbonate particles can be seen in the micrograph of impact tested specimen.

this case again about $150 \%$ increase in the impact strength, compared to unfilled composites, was observed. Volume fraction of calcium carbonate particles was kept $9 \%$, which was higher than that of flyash particles. Due to poor strength of these particles they tend to break by the advancing crack (figure 7 ). In this case additional amount of energy is absorbed in fracture of these particles in addition to the crack tip blunting effect, again leading to increase in impact strength.

\section{Conclusions}

Addition of filler particles in small volume fractions led to the decrease in compressive strength of the composite specimens. However, impact strength by such addition increased considerably. Effect of aspect ratio of the specimen on the compressive strength of the material is significant and cannot be neglected. Specimen behaviour was found to vary considerably with the change in aspect ratio; it also affected the values of compressive strength. In case of short fibre composites, fibre length should always be considered while deciding upon specimen dimensions and aspect ratio. In case of impact mode of fracture, it greatly depends upon the interfacial strength of the filler and matrix material.

\section{References}

ASTM C618-99 Standard specification for coal flyash and raw or calcined natural pozzolan for use as a mineral admixture in concrete

ASTM D695-96 Standard test method for compressive properties of rigid plastics

Gupta N, Karthikeyan C S, Sankaran S and Kishore 1999 Mater. Char. 14271

Katz H S and Milewski J V (eds) 1987 Handbook of fillers for plastics (Reinhold: Von Nostrand)

Helmuth Richard 1987 Flyash in cement and concrete (Illinois: Portland Cement Association) p. 36

Monette L and Anderson M P 1993 Scr. Metall. Mater. 281095

Srivastava V K 1992 Eng. Fract. Mech. 431093

Srivastava V K, Shembekar P S and Prakash R 1988 Comp. Struct. 10271

Vrastsanos L A and Farris R 1993 Polym. Eng. \& Sci. 331458

Wong K W Y and Truss R W 1994 Comp. Sci. \& Technol. 52 361 